\title{
Health and Well-Being of Immigrant Children and Youth
}

\author{
Cherylynn Bassani \\ Department of Social, Cultural and Media Studies, University of the Fraser Valley, 33844 King Road, \\ Abbotsford, BC, Canada V2S 7M8 \\ Correspondence should be addressed to Cherylynn Bassani, cherylynn.bassani@ufv.ca
}

Received 15 July 2012; Accepted 15 July 2012

Copyright (C) 2012 Cherylynn Bassani. This is an open access article distributed under the Creative Commons Attribution License, which permits unrestricted use, distribution, and reproduction in any medium, provided the original work is properly cited.

This special issue includes a wide spectrum of research papers: using qualitative, quantitative, and mixed methods; from a variety of countries (Australia, Canada, and the United States of America); examining a diverse array of immigrant children and their families. While some of the research follows a more "traditional" academic research approach, others are the product of program analyses. One thing, however, that all of the papers have in common is that they all focus on a marginalized immigrant group. This special issue is not only interesting, but it is encouraging to see scholars from around the world centre their attention on the health of marginalized children.

It has been a delight to edit this special issue. I thank my coeditors Dr. A. George and Dr. U. Tran for their efforts. We would like to thank the many researchers that sent in manuscripts to be included in this issue. The health and well-being of immigrant children is an important issue that needs our attention and dedication. While funding for such research tends to be limited, especially in the current global economic climate, I would encourage readers from all countries to continue on in their efforts to showcase the health disparities and related inequalities that immigrant children and their families endure. By doing this we can highlight the existing inequalities to policy makers and governments and collectively make a difference in the well-being of future generations.

Dr. U. Tran (MD) is a developmental paediatrician and researcher in Queensland, Australia. Her paper showcases the results of a pilot study that compared perceived parenting roles, child development, health service utilization, as well as child health, illness, and disability among Vietnamese immigrants in Australia versus Australian-born Caucasians. Her research makes a valuable contribution to what is known about Vietnamese immigrants' perceptions of health and health care practices, particularly in the Australian context since scant research can be found on the topic. Dr. U. Tran concludes that key differences between Vietnamese immigrant and Australian-born Caucasian parents were detected and that the immigrant parents were not only less familiar with health services that were available for their children, but they were also less satisfied with the mainstream services that they had utilized. These findings suggest that a better understanding of the health care needs of specific (i.e., immigrant) populations is warranted.

Dr. T. Tuma $(\mathrm{PhD})$ is a researcher at the Hasbro Children's Hospital Refuge Health Clinic in Rhode Island, USA. Together with her colleagues, Ms. L. Ratanaprasatporn, Dr. D. J. Watts (MD), and Dr. C. Lewis (MD), this team of researchers present their evaluation of the refugee "medical home"- the Hasbro Children's Hospital's Refugee Health Clinic that was established in 2007 to serve the health needs of refugee families in the Rhode Island area. Their evaluation illustrates truly amazing results; the medical home model has increased screening rates to $100 \%$ and increased completion of TB treatment to $100 \%$. In addition, missed appointments dramatically declined (compared to the former nonfamily centred care). This refugee healthcare model is one that policy makers, health funders, and health authorities should take note of and consider implementing elsewhere.

Dr. J. C. Rauch (MD) and his colleagues Dr. M. McCord (MD), Ms. M. Batista and Dr. E. Anisfeld report on the influence of social background and the Healthy Families America Home Visiting program on the health of a largely Dominican immigrant population. Their research adds to what is known about the health of immigrant families and their children, but perhaps most importantly Dr. J. C. Rauch and his colleagues illustrate a delayed effect of the Home Visiting program on the families that participated in the study. 
This is particularly noteworthy for program developers, funders, and other stakeholders, as funding is only typically given for short segments of time. These findings suggest that long-term investments are needed to reap maximum health benefits for families and their children.

Ms. N. Iqbal, a community development worker from Cardinia Casey Community Health Service, Dr. A. Joyce, a researcher and lecturer at Monash University in Victoria, Australia, Ms. A. Russo, a health promotion worker from Cardinia Casey Community Health Service, and Dr. J. Earnest, associate professor at Curtin University in Western Australia present an interesting piece on the resettlement experiences of female Afghan Hazara youth in Melbourne, Australia. Considering the recent surge of Afghan refugees around the world, this piece is of particular importance; not only do the authors give these girls a voice but their research also uncovers a number of issues that need further examination and have direct policy and program implications. A central finding that the authors uncover is the importance of cultural connections both within the refugee community and the broader community. The creation of social capital, and ultimately cultural capital (in dominant and subdominant groups), appears to be pivotal in understanding the girls' health and well-being.

Dr. A. George (PhD), associate professor at the University of British Columbia in the Department of Pediatrics in Prince George British Columbia, Dr. C. Bassani (PhD), researcher and lecturer at the University of the Fraser Valley in Abbotsford British Columbia, and Dr. R. Armstrong (PhD, MD), Dean of Medicine at Aga Khan University in East Africa, examine the influence of perceived racial/ethnic discrimination on the health and behaviour of ethnic minority immigrant children in Canada. Their research is especially noteworthy since few publications have linked discrimination to the health of immigrant children. They highlight the particularly negative effect that perceived discrimination against the individual and ethnic group has on a variety of child's health measures. Their research also highlights the importance of considering "immigrant" children as a heterogeneous group.

Dr. K. Soldatic from Curtin University in West Australia, Dr. H. Meekosha from the University of New South Wales, and Dr. K. Somers from Curtin University provide an intriguing analysis of Australia's exclusionary and discriminatory immigration policy through the case of "Ernesto." Through the single case method approach, the researchers explore the intersectionality of temporary migration, disability, childhood, and health. The aim of this research is political-to showcase the need for civil society groups, community groups, researchers, and teachers to heighten their voices so to challenge the Australian government's discriminatory policy on disability. It is our hope that readers will heed their recommendations. 


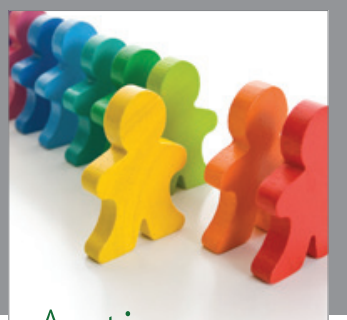

Autism

Research and Treatment
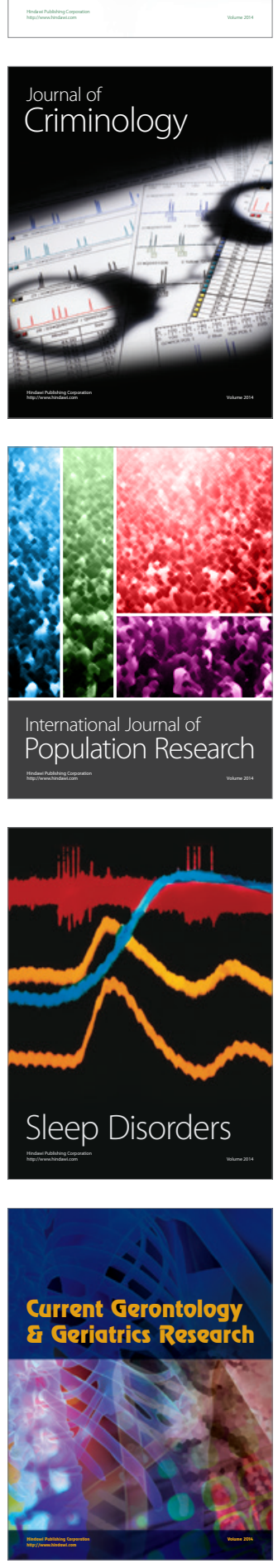
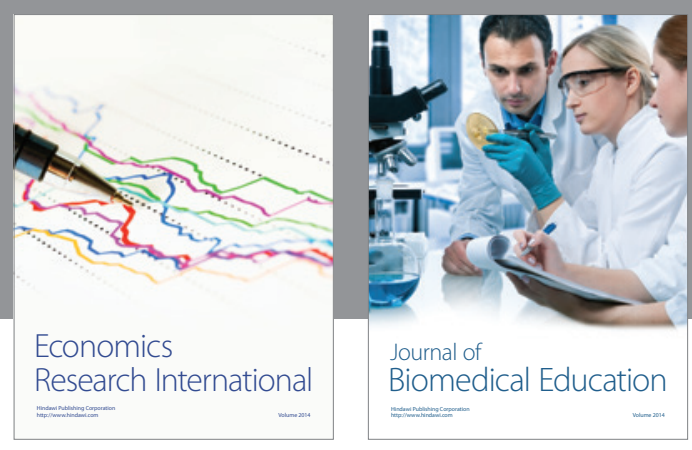

Journal of

Biomedical Education

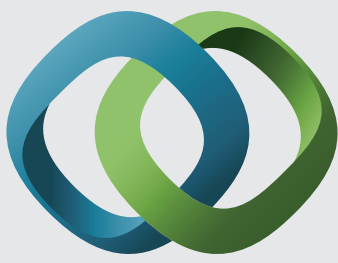

\section{Hindawi}

Submit your manuscripts at

http://www.hindawi.com
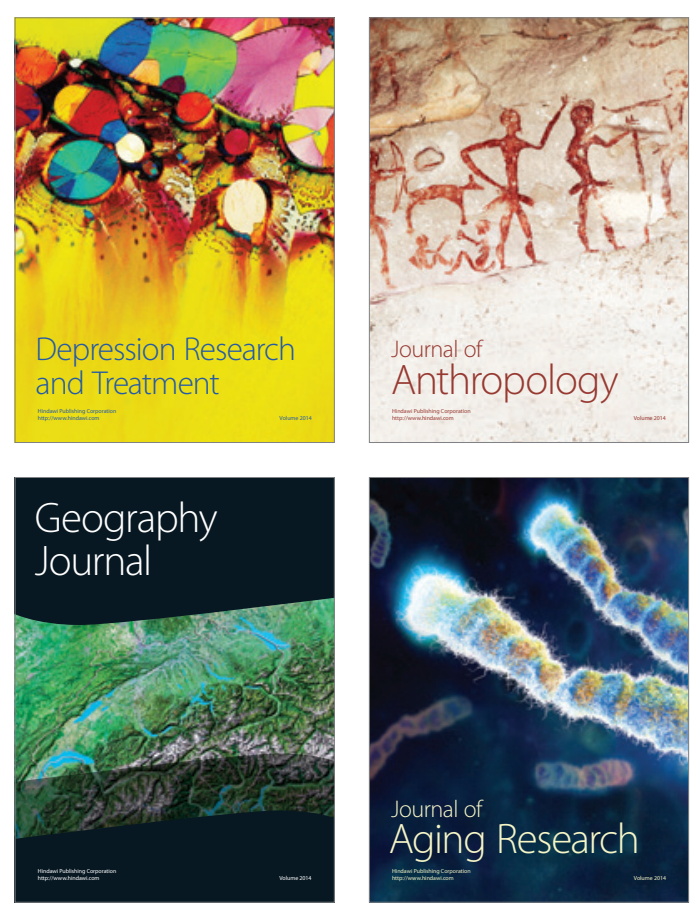

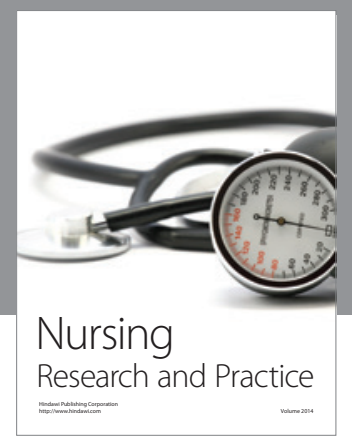

Nursing

Research and Practice

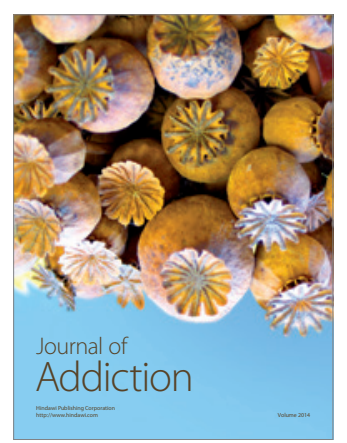

Child Development

Research

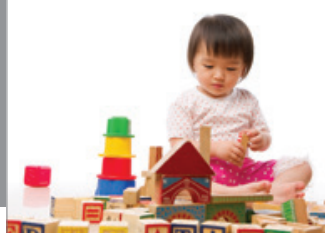

迥
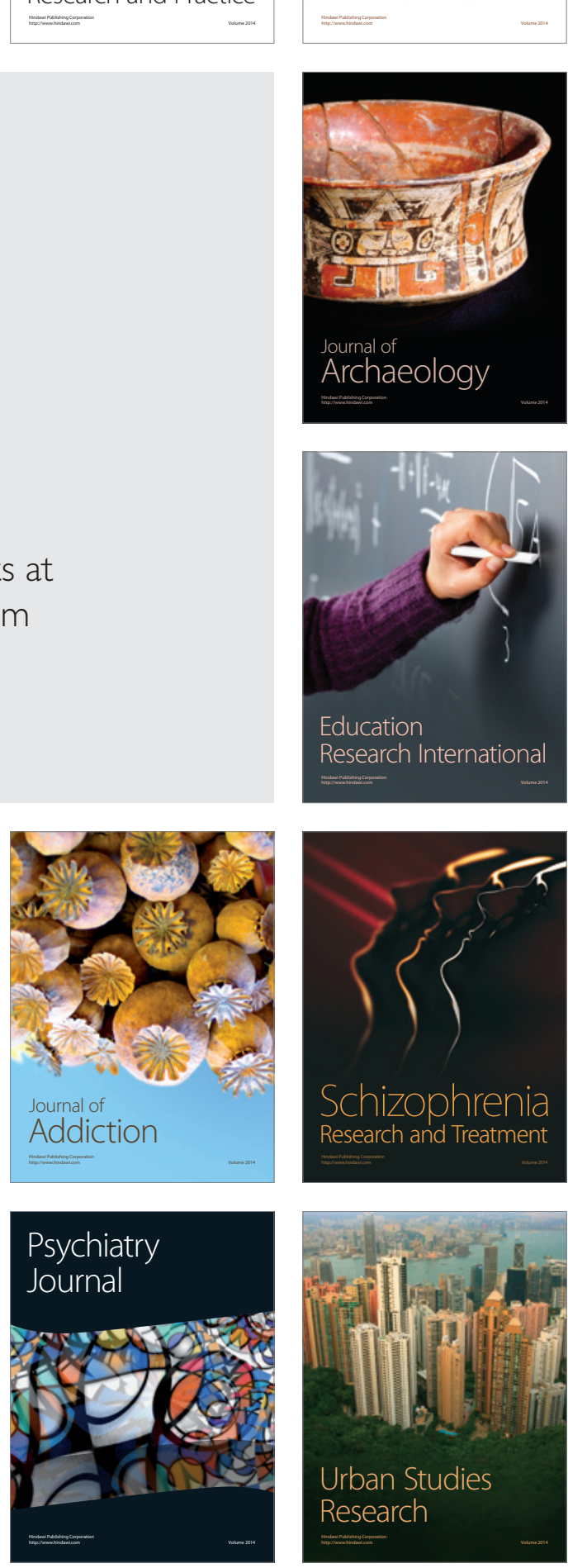